\title{
Eingesandte Bücher
}

Büchner, Karl: Römische Literaturgeschichte. Thre Grundzüge in interpretierender Darstellung. (Kröners Taschenausgabe. Bd 247.) Stuttgart: A. Kröner 1957. (580 S. kl. $8^{\circ}$ ) Leinen DM I 5.-

Lesky, Albin: Geschichte der griechischen Literatur. Lfrg 4/5, 6/7. Bem: A. Francke 1957. (S. 193-320, 321-448, gr. $8^{\circ}$ ) Je DM 9.20

Müri, Walter: Die Antike. Untersuchung über den Ursprung und die Entwicklung der Bezeichnung einet geschichtlichen Epoche. Bern: Städt. Gymnasium I957. (60 S. 80)

Tacitus: Annalen. Aus d. Latein. v. August Horneffer. Mit e. Einleitg. v. Joseph Vogt u. Anmerkungen v. Werner Schur. Mit 7 Taf. 2. Auf. (Kröners Taschenausgabe. Bd 238.) Stuttgart: A. Kröner 1957. (XLII, 6r I S., I Kt., kl. 80) Leinen DM 13.50

Ammon, Hermann: Deutsche Literaturgeschichte in Frage und Antwort. Bd $\mathrm{x}$ : Von den Anfängen bis 1500. 5., neubearbeitete Auf. Bonn: Ferd. Dümmlers Verlag 1957. (104 S. $8^{\circ}$ ) Karton. DM 5.95

Bonaventura: "De triploci via in altschwäbischer Übertragung hrsg. v. Kurt Ruh. (Texte des späten Mittelalters. H. 6.) Berlin: Erich Schmidt Verlag I957. (64 S. 80) DM 5.20

Brand, C. P.: Italy and the English Romantics. The italianate fashion in early nineteenthcentury England. Cambridge: The University Press 1957. (XI, 285 S., 8 Taf. $8^{0}$ ) Leinen $35 /-$ net.

Curtius, Ernst Robert: Europäische Literatur und lateinisches Mittelalter. 2., durchges. Auf. Bern: A. Francke I954. (608 S. gr. $\left.8^{\circ}\right)$ Leinen DM 28.80

Grimm, Wilhelm: Die deutsche Heldensage. 4. Aufl. Unter Hinzufügung der Nachträge von Karl Müllenhoff und Oskar Jänicke aus der Zeitschrift für Deutsches Altertum. Darmstadt: Hermann Gentner Verlag 1957. (XXIX, 724 S. $8^{\circ}$ ) Leinen DM 28.-

Hirsch, Arnold: Bürgertum und Barock im deutschen Roman. Zur Entstehungsgeschichte des bürgerlichen Weltbildes. 2. Aufl, besorgt v. Herbert Singer. (Literatur u. Leben. NF, Bd x.) Köln: Böhlau Verlag 1957. (XII, 163 S. 80) Karton. DM i 2.80

Hamburger, Käte: Die Logik der Dichtung. Stuttgart: Ernst Klett Verlag I957. (VIII, 255 S. $8^{\circ}$ ) Leinen DM 17.80

Im Utteil der Dichter. Die deutsche Literatur von Lessing bis Hauptmann. Hrsg. v. Amo Mulot. München: Bayer. Schulbuch-Verlag 1957. (XV, $35^{\circ}$ S. $8^{\circ}$ ) Leinen DM 12.80

Kayser, Wolfgang: Das Groteske. Seine Gestaltung in Malerei u. Dichtung. Oldenburg: G. Stalling I957. (228 S., 32 S. Abb. $8^{0}$ ) Leinen DM 16.80

Kluge, Friedrich: Unser Deutsch. Einführung in die Muttersprache. 6. Aufl., hrsg. v. Lutz Mackensen. Heidelberg: Quelle \& Meyer I957. (I 8 S. kl. $8^{\circ}$ ) Halbleinen DM 6.-

von der Leyen, Friedrich: Das Märchen. Ein Versuch. 4., erneuerte Aufl. unter Mitarbeit v. Kurt Schier. Heidelberg: Quelle \& Meyer 1958 . (186 S. kl. $8^{\circ}$ ) Halbleinen DM 6.50

May, Kurt: Form und Bedeutung. Interpretationen deutscher Dichtung des 18 . und r9. Jahrhunderts. Stuttgart: Ernst Klett Verlag 1957. (3 I4 S. $8^{\circ}$ ) Leinen DM I6.80

Newald (†), Richard: Von Klopstock bis zu Goethes Tod. I750-1 832. Tl I: Ende der Auf klärung und Vorbereitung der Klassik. (de Boor/Newald: Geschichte der deutschen Literatur. Bd VI/r.) München: C. H. Beck 1957. (IX, 438 S. 80) DM I6.50, Leinen DM 21.-

Schwonke, Martin: Vom Staatsroman zur Science Fiction. Eine Untersuchung über Geschichte und Funktion der naturwissenschaftlich-technischen Utopie. (Göttinger Abhandlungen zur Soziologie. Bd 2.) Stuttgart: Ferdinand Enke 1957. (VII, I94 S. gr. $\left.8^{0}\right)$ DM r6.- 